\section{Sampling indigenous ground-living beetles in a stand of non-native tree privet (Ligustrum lucidum) in New Zealand raises new management questions}

\author{
Dan Blanchon ${ }^{1}$, John Pusateri ${ }^{2}$, Mel Galbraith ${ }^{1}$ and \\ Stephen Thorpe ${ }^{3}\left({ }^{1}\right.$ Department of Natural Sciences, Unitec \\ Institute of Technology, Private Bag 92025, Auckland, \\ New Zealand; Tel: 649815 4321; Email: dblanchon@ \\ unitec.ac.nz; ${ }^{2}$ Department of Architecture, Unitec Institute \\ of Technology, Private Bag 92025, Auckland, New \\ Zealand; ${ }^{3}$ School of Biological Sciences, University of \\ Auckland, Private Bag 92019, Auckland, New Zealand).
}

Key words: beetle assemblages, Coleoptera, indigenous species, introduced species, Ligustrum lucidum, New Zealand.

\begin{abstract}
Summary
Small urban forest reserves in New Zealand have been shown to have value in conserving indigenous beetle diversity. However there is little information available on the ability of non-native vegetation areas such as tree privet to support indigenous beetle assemblages. To investigate this for one site, ground-living beetles were collected using pitfall traps over a year at a small urban forest of the invasive tree Ligustrum lucidum (tree privet) in Auckland, New Zealand. A total of 815 beetles were found, from 20 families and 42 relative taxonomic units. Using monthly data, there was no correlation between soil moisture and diversity index $(P=0.805)$ or species richness $(P=0.375)$. These results raise the question of whether urban patches of non-native tree privet may have potential as reservoirs of beetle diversity, if only until they are replaced with native vegetation.
\end{abstract}

\section{Introduction}

Many forest fragments and regenerating forest areas in northern New Zealand have been invaded by tree privet or large-leaved privet (Ligustrum lucidum W.T. Aiton), originally native to China and Korea and now invasive in New Zealand, Australia and Argentina (Lichstein et al. 2004). Invasion of forest in Argentina by this species has been linked to a reduction in native tree recruitment, possibly caused by lowered light levels and soil fertility, with a high mortality of native saplings (Lichstein et al. 2004). Research on Ligustrum-dominated forests has found reduced species richness of other plants and influences on the behaviour of frugivores because of different phenology from the native flora (Grau et al. 2008). Replacement of native vegetation with non-native plants can potentially affect invertebrate numbers and species composition, in turn having effects on other trophic levels (Herrera \& Dudley 2003). Invasive plants are unlikely to provide appropriate food sources for native invertebrate herbivores, unless the non-native plant has close relations in the local flora (Ernst \& Cappuccino 2005). While it is not known what the effect of tree privet replacing native forest has on beetle diversity, it is likely that forest floors with reduced native plant species and cover are likely to also lack other native species, including insects (Ulyshen et al. 2010). Currently, most local authorities in New Zealand have a policy of removing tree privet and replacing it with native vegetation, but it is not known what impact on biodiversity, if any, could result from this process.

The objective of this study was to gain an insight into the level of diversity of ground beetles that was supported by a stand of tree privet, and therefore, what may need to be considered when restoring the site. Ground-living beetles were studied as it is considered that they are easily surveyed with pitfall traps, are generally good dispersers and may survive in fragmented landscapes (Lövei \& Cartellieri 2000). Soil moisture was tracked over the study period as this may affect species composition.

\section{Methods}

The study was undertaken at Jaggers Bush $\left(36^{\circ} 51^{\prime} 33.79^{\prime} \mathrm{S}\right.$ $174^{\circ} 43^{\prime} 10.69^{\prime} \mathrm{E}, 19 \mathrm{~m}$ altitude), a 2.6-ha homogenous forest of tree privet (L.lucidum) within the urban matrix of Auckland city. Sections of this forest are currently being slowly converted to native vegetation.

Twelve pitfall traps were positioned on each of two 25$\mathrm{m}$ parallel transects $6 \mathrm{~m}$ apart in relatively uniform soil conditions at the centre of the largest area of privet trees with no indigenous vegetation present. Each transect consisted of six traps $4 \mathrm{~m}$ apart from each other. Traps were set with $30 \mathrm{~mL}$ of $10 \%$ saline solution. Traps were cleared after 1 week and were set twice every 4 weeks over a 12-month period (22 May 2007-19 May 2008). Pitfall traps have been used widely in New Zealand to sample grounddwelling beetles (e.g. Crisp et al. 1998; Watts \& Larivière 2004), but it should be acknowledged that capture rates do not necessarily reflect the real abundance of species at a site as collection is affected by the activity of the species and density of the population (Crisp et al. 1998; Watts \& Larivière 2004). Beetles were cleaned in tap water and placed in labelled jars or vials of $70 \%$ ethanol for later identification.

Soil samples were taken at 4 weekly intervals. A 10$\mathrm{cm}$-diameter core was taken to $15 \mathrm{~cm}$ depth, and fresh 100 -g samples were taken from this, dried for $24 \mathrm{~h}$ at 
$105^{\circ} \mathrm{C}$ and reweighed to determine the percentage of soil moisture.

Data were analysed for summary statistics, and a Pearson's product moment correlation analysis was undertaken on a diversity index, species richness and soil moisture using PASW (Predictive Analytics Software Statistics) software (Armonk, New York, USA).

\section{Results}

A total of 815 individual beetles were collected, consisting of 42 RTUs (Relative Taxonomic Unit, referred to from now on as species), in 20 families. The most species rich families were the Curculionidae, Scarabaeidae and Staphylinidae. Nine of the species were definitely introduced with the remaining 33 either native or assumed to be native (some taxa were only able to be identified to genus level). As expected, beetle diversity increased from spring to summer. A range of trophic groups were identified.

Soil moisture fluctuated widely over the year (17.1$36.87 \%$ ), and moisture levels were generally lower in summer (Fig. 1).

Using monthly data, a Pearson's product moment correlation analysis indicated that there is no correlation between soil moisture and diversity index $(r=-0.076$, $P=0.805)$ or between soil moisture and species richness $(r=-0.269, P=0.375)$.

\section{Discussion}

Unexpectedly, the overall native species richness (33 species) in the 2.6-ha area of tree privet compares favourably with two urban reserves of native vegetation surveyed by Watts and Larivière (2004). They recorded 26 native beetle species at a 19-ha reserve and 18 species at a 6.3-ha site, although it must be noted that their study was performed over 2 months only, so it could be expected that the species richness at those two sites is actually much higher.

This is unexpected because most studies have found that non-native vegetation supports a lower diversity of invertebrates than native vegetation. For example, Crisp et al. (1998) found that areas on the south coast of Wellington, New Zealand, with a large proportion of introduced Gorse (Ulex europaeus) had lower percentages of native beetle species than habitats with higher proportions of native vegetation. Ulyshen et al. (2010) studied another species of Ligustrum, L. sinense, a non-native invasive in Georgia, United States of America. They removed $L$. sinense from areas of native flood plain forests and found that this greatly increased beetle richness near the ground, resulting in diversity similar to that in native forests lacking L. sinense.

While the lack of replication and small sample size of the study mean that there is a possibility that the results are caused by some chance factor, it is interesting to speculate that a possible explanation for the result at this site may be that the current management practice outside the study site of underplanting with native trees and shrubs, careful removal of individual privet trees (Happy 2009) and leaving the deadwood at the site could be providing a range of microhabitats, supporting the high abundance, relatively high species richness and spread of trophic groups at the site. In addition, the privet forest at Jaggers Bush is within a mosaic of private gardens, parks and sports fields, and this may be contributing to the beetle diversity. Crisp et al. (1998) found relatively high numbers of native beetle species in human-modified areas and recommended conserving both natural and semi-natural areas to preserve maximum biodiversity.

There was no correlation between soil moisture and species richness or diversity, despite wide fluctuations in soil moisture over the study period. In native forests, Watts and Larivière (2004) found that soil moisture appeared to be a factor correlated with beetle diversity. They also attributed the high diversity of beetles in the Waitakere Ranges sites to the continuous layer of litter, presence of deadwood and higher soil moisture at these sites. Moisture levels were generally higher, and fluctuated less (23.77-35.03\%), in a parallel recording

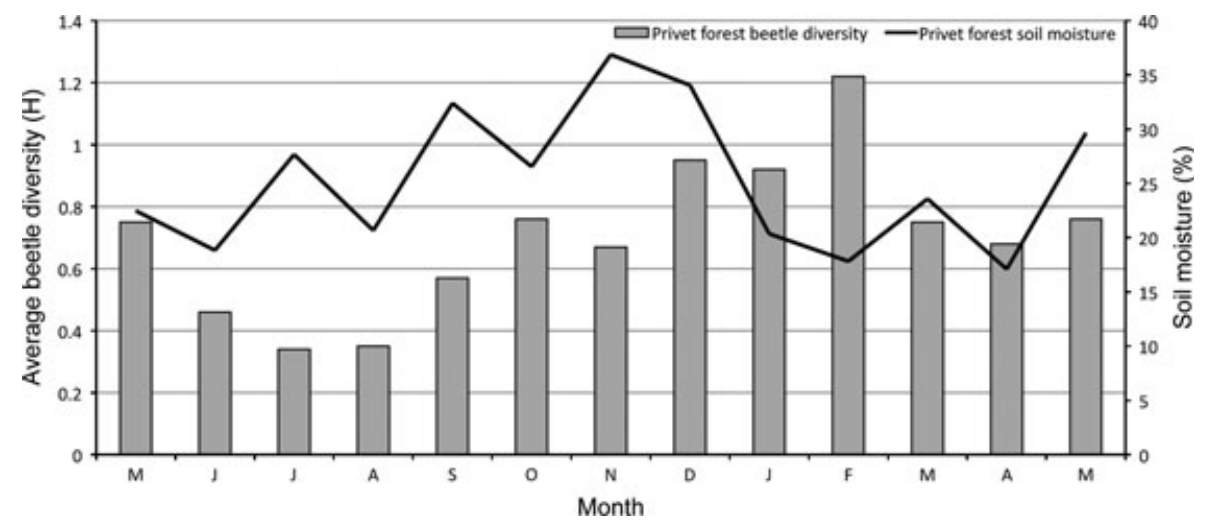

Figure 1. Comparison of beetle diversity (Shannon Diversity index (H) (bar chart) with soil moisture (\%) (lines) for privet forest at Jaggers Bush. 
of soil moisture in the nearest native forest over the same time period (Dan Blanchon, unpublished data, 2011). At the tree privet study site, the forest floor is largely devoid of cover, with only a seasonally variable layer of leaf litter (up to $15 \mathrm{~cm}$ thick between November and March, largely absent between April and October). The soil is well-drained and friable, on a ridge slope above a small flood plain, so is likely to be drier than surrounding areas.

Watts and Larivière (2004) found that even small, isolated urban forest reserves have potential as reservoirs of beetle diversity. The results of our study raise the question of whether urban patches of non-native vegetation may also have potential, if only until they are replaced with native vegetation, although the very small sample size of our study prevents us from drawing any generalizations. Watts and Gibb (2000) found that restoration of native vegetation is linked to an increase in diversity and abundance of native beetles, but they also noted that revegetating degraded ecosystems usually causes disturbance and that the time necessary for a beetle fauna to re-establish is not known. This raises the further question of whether the current 'rolling front' management regime of underplanting with indigenous plant species and gradual, staged removal of individual privet trees (Happy 2009) may offer a useful approach to optimizing habitat values during the restoration process. The stated rationale for this approach is to reduce reinvasion by weed species and to prevent erosion, but should it also minimize disturbance of the forest floor and the diversity of its invertebrates, then additional benefits may arise for invertebrate diversity. In our view, therefore, it would be useful to repeat this study over a wider range of similar sites (under different treatments) to test both these questions.

\section{Acknowledgements}

We would like to thank Rick Kooperberg for technical assistance, Auckland City Council and Tony van Raat for access to sites, Nigel Adams for statistical advice and the Unitec Research Committee for providing funding.

\section{References}

Crisp P. N., Dickinson K. J. M. and Gibbs G. W. (1998) Does native invertebrate diversity reflect native plant diversity? A case study from New Zealand and implications for conservation. Biological Conservation 83. 209-220.

Ernst C. M. and Cappuccino N. (2005) The effect of an invasive alien vine, Vincetoxicum rossicum (Asclepidaceae), on arthropod populations in Ontario old fields. Biological Invasions 7, 417-425.

Grau H. R., Hernández M. E., Gutierrez J. et al. (2008) A peri-urban neotropical forest transition and its consequences for environmental services. Ecology and Society 13(1), 35.

Happy S. (2009) Jaggers Bush Restoration Plan. Te Ngahere/Auckland City Council, Auckland.

Herrera A. M. and Dudley T. L. (2003) Reduction of riparian arthropod abundance and diversity as a consequence of giant reed (Arundo donax) invasion. Biological Invasions 5, 167-177.

Lichstein J. W., Grau H. R. and Aragón R. (2004) Recruitment limitation in secondary forests dominated by an exotic tree. Journal of Vegetation Science 15, 721-728.

Lövei G. L. and Cartellieri M. (2000) Ground beetles (Coleoptera, Carabidae) in forest fragments of the Manawatu, New Zealand: Collapsed assemblages? Journal of Insect Conservation 4, 239-244.

Ulyshen M. D., Horn S. and Hanula J. L. (2010) Response of beetles (Coleoptera) at three heights to the experimental removal of an invasive shrub, Chinese privet (Ligustrum sinense), from floodplain forests. Biological Invasions 12, 1573-1579.

Watts C. H. and Gibb G. W. (2000) Species richness of indigenous beetles in restored plant communities on Matiu-Somes Island, Wellington Harbour, New Zealand. New Zealand Journal of Ecology 24, 195200.

Watts C. H. and Larivière M. (2004) The importance of urban reserves for conserving beetle communities: a case study from New Zealand. Journal of Insect Conservation 8, 47-58.

\section{Influence of Lantana camara and its removal on tree dynamics in a recently burnt wet Sclerophyll forest in Northern NSW}

Alice G. Yeates ${ }^{1}$ and Shon S. Schooler ${ }^{2}\left({ }^{1}\right.$ The University of Queensland, School of Biological Sciences, St Lucia, QLD 4072, Australia; Email: a.yeates1@uq.edu.au; ${ }^{2}$ CSIRO Ecosystem Sciences, EcoSciences Precinct, PO Box 2583, Brisbane, QLD 4001, Australia).

Key words: alien, disturbance, impacts, introduced, invasive, seedling, splatter gun.

\begin{abstract}
Summary
Lantana (Lantana camara) has adverse effects on plant communities across Australia. Fire, sometimes recommended as a management strategy for Lantana, is likely to have both beneficial and detrimental effects on Lantana and native trees. It is therefore important to evaluate the regeneration of Lantana-invaded woody plant communities postfire. We examined the effect of Lantana removal by herbicide spray on both Lantana density and small tree ( $<5 \mathrm{~cm}$ diameter at breast height; DBH) attributes (abundance, height, DBH and diversity) in an area previously burnt. On a subset of the data, which was not sprayed, we also examined small tree attributes along a gradient of Lantana density. The herbicide treatment of postfire Lantana regrowth significantly reduced Lantana density compared to the areas left unmanaged by herbicide and increased
\end{abstract}

